\title{
Histopathologic Profile of Premalignant and Malignant Lesions of Gallbladder
}

Binita Goyal'

'Department of Pathology, College of Medical Sciences, Bharatpur, Chitwan, Nepal.

\begin{abstract}
Introduction

Neoplastic lesions of gallbladder are less well defined than other lesions in gastrointestinal tract due to rarity of lesions and also poor accessibility of this site. More than fifty percent cases of cancer are clinically missed. This study was aimed to see the histopathologic spectrum of premalignant and malignant lesions, compare clinical diagnosis with histopathological diagnosis and see association between gross morphology and missed clinical diagnosis.
\end{abstract}

\section{Methods}

This study was conducted on 56 consecutive cases of premalignant and malignant lesions of gallbladder received in study period of 10 years from January 2011 to December 2020.

\section{Results}

Age of the patients ranged from $13-84$ years with a mean \pm SD of $56.8 \pm 13.7$ years with maximum $17(30.4 \%)$ cases in $41-50$ years age group. There were $14(25.0 \%)$ males and $42(75.0 \%)$ females with a male female ratio of 1:3. 10 (17.9\%) cases were premalignant lesions and $46(82.1 \%)$ cases were malignant lesions. $93.5 \%$ malignant cases were adenocarcinoma. $41.3 \%$ cases were clinically not suspected to be malignant. There was no association between gross morphology and missed clinical diagnosis $(p>0.05)$.

\section{Conclusions}

Routine histopathologic examination of all the resected gallbladder specimens is manadatory as important diagnosis can be missed.

Keywords: gallbladder; gallbladder cancer; malignant; premalignant

Correspondence: Dr. Binita Goyal. Department of Pathology, College of Medical Sciences, Bharatpur, Chitwan, Nepal. Email: binitagoyal@yahoo.com. Phone: +977-9860167741. 


\section{INTRODUCTION}

Gallbladder is a pear shaped muscular sac attached to the posterior aspect of right lobe of liver. ${ }^{1,2}$ Between meals bile is stored in the gallbladder where it is concentrated. ${ }^{3}$ During and after a fatty meal, it contracts delivering the bile through the bile ducts into the intestine to help with digestion. ${ }^{4}$

Gallbladder can be a site of various disease processes like congenital anomalies, acute and chronic inflammation, cholelitihiasis, benign and premalignant conditions and cancer. ${ }^{3,5}$ More than ninety five percent of biliary tract diseases are attributed to gall stone disease. Though uncommon, gallbladder cancer (GBC) is most common cancer of extrahepatic bililary tract. $^{3}$ According to Global cancer statistics (GLOBOCAN 2020) GBC accounts for age standardized incidence rate of $1.2 \%$ and mortality rate of $0.84 \%$ and Asia has the highest burden comprising $70.8 \%$ of new cases and $73.6 \%$ deaths due to GBC. ${ }^{6}$

Two distinct epithelial lesions, adenoma and dysplasia, also termed as biliary intraepithelial neoplasia (Bil IN)are considered premalignant conditions in gallbladder carcinogenesis., ${ }^{7,8}$ Intracholecystic papillary neoplasm (ICPN) is a relatively new entity encompassing all neoplastic polyps, preinivasive adneomas and intracystic papillary neoplasms $\geq 1 \mathrm{~cm}$ in diameter irrespective of phenotype of tumor cells and is considered a premalignant condition. ${ }^{9-11}$

Only 1 in 5 cases of GBC are diagnosed at an early stage in United States and median survival of advanced stage cancer is not more than a year. ${ }^{4}$ Approximately fifty percent of gallbladder carcinomas are diagnosed incidentally in cholecystectomy specimens with gall stone disease and even when found incidentally, tend to present at a late stage. ${ }^{12}$ If the protocol of routine histopathological examination of all gallbladder specimens is not followed, subclinical malignancies may be missed with disastrous results. ${ }^{13}$

Hence, this study is conducted to see spectrum of various premalignant and malignant conditions of gallbladder, compare their clinical diagnosis with histopathological diagnosis and see association between gross morphology and missed clinical diagnoses.

\section{METHODS}

This retrospective chart review was carried out in Department of Pathology, College of Medical Sciences and Teaching Hospital. Ethical approval from the Institutional Review Committee was obtained (reference no. COMSTH-IRC/2021-39). 56 consecutive cases of premalignant and malignant lesions of gallbladder received in cholecystectomy specimens in histopathology section of Department of Pathology of College of Medical Sciences and Teaching Hospital during a time period of 10 years from January 2011 to December 2020 were included in the study. All the premalignant and malignant lesions were included. Inflammatory and other non-neoplastic polyps and conditions were excluded. Tumors of biliary tree were excluded. Recurrent tumors were also excluded. Malignancies were classified and staged according to World Health Organization Classification of Tumors (fourth edition). ${ }^{12}$ All the cases of premalignant and malignant lesions received in the study period were reviewed from the departmental records. Data was initially entered in MS-Excel, refined and finally analyzed by SPSS 20.0. Variables like age at presentation, gender, site, gross type, histological type, differentiation and extent of tumor invasion were analyzed. Continuous variables were expressed as mean \pm standard deviation (SD) and categorical variables were expressed as frequencies and percentages. Histological diagnosis was compared with 
clinical diagnosis. Association between clinical diagnosis and gross morphology were sought for malignant cases using Pearson chi square test and likelihood ratio was calculated and level of significance was calculated at 95\% confidence interval.

\section{RESULTS}

Altogether 56 cases of premalignant and malignant lesions were received in the study period. Age of the patients ranged from $13-84$ years with a mean \pm SD of $56.8 \pm 13.7$ years with maximum $17(30.4 \%)$ cases in 41 - 50 years age group. There were $14(25.0 \%)$ males and 42 $(75.0 \%)$ females with a male female ratio of $1: 3$ (Table 1). $10(17.9 \%)$ cases were premalignant lesions and $46(82.1 \%)$ cases were malignant lesions with maximum 14 (30.4\%) malignant cases in $41-50$ years age group (Figure 1 ).
Table 2. Histological diagnoses of premalignant and malignant lesions $(n=56)$

\begin{tabular}{|l|l|l|}
\hline S.N & Histological diagnoses & $\begin{array}{c}\text { Number } \\
(\%) \text { of } \\
\text { cases }\end{array}$ \\
\hline \multicolumn{2}{|l|}{ Premalignant lesions } & \multicolumn{1}{|l|}{$4(7.1)$} \\
\hline & BillN & $3(5.4)$ \\
\hline & Adenoma & $3(5.4)$ \\
\hline & ICPN (Fig 2) & $39(69.6)$ \\
\hline Malignant lesions & Adenocarcinoma & $4(7.1)$ \\
\hline & $\begin{array}{l}\text { Intracholecystic papillary neoplasm } \\
\text { with invasive carcinoma }\end{array}$ & $2(3.6)$ \\
\hline & Undifferentiated carcinoma (Fig 3) & $1(1.8)$ \\
\hline & Adenosquamous carcinoma (Fig 4) & $56(100)$ \\
\hline Total &
\end{tabular}

Table 1: Age and gender distribution of cases $(n=56)$

\begin{tabular}{|c|c|c|c|}
\hline Age group (years) & Malen (\%) & Female $\mathbf{n}(\%)$ & Total $\mathbf{n}(\%)$ \\
\hline$\leq 40$ & $2(3.6)$ & $2(3.6)$ & $4(7.1)$ \\
\hline $41-50$ & $5(8.9)$ & $12(21.4)$ & $17(30.4)$ \\
\hline $51-60$ & $0(0)$ & $12(21.4)$ & $12(21.4)$ \\
\hline $61-70$ & $4(7.1)$ & $11(19.6)$ & $15(26.8)$ \\
\hline $71-80$ & $1(1.8)$ & $3(5.4)$ & $4(7.1)$ \\
\hline$>80$ & $2(3.6)$ & $2(3.6)$ & $4(7.1)$ \\
\hline Total & $14(25)$ & $42(75)$ & $56(100)$ \\
\hline
\end{tabular}

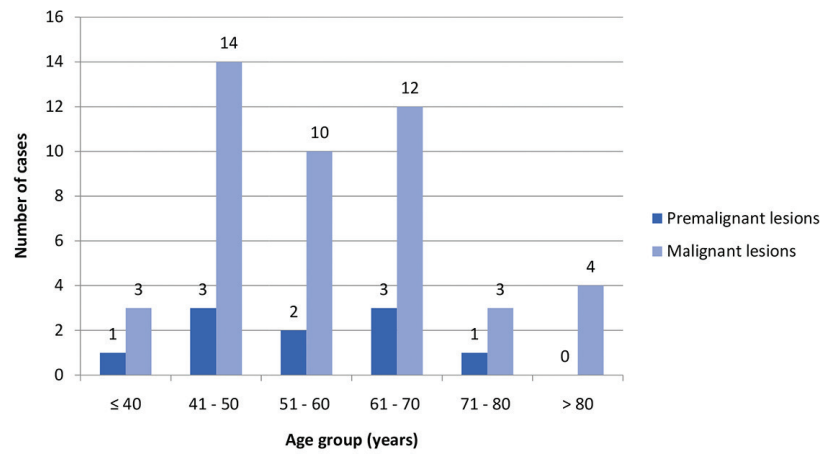

Figure 1. Bar diagram showing age distribution of premalignant and malignant lesions $(n=56)$

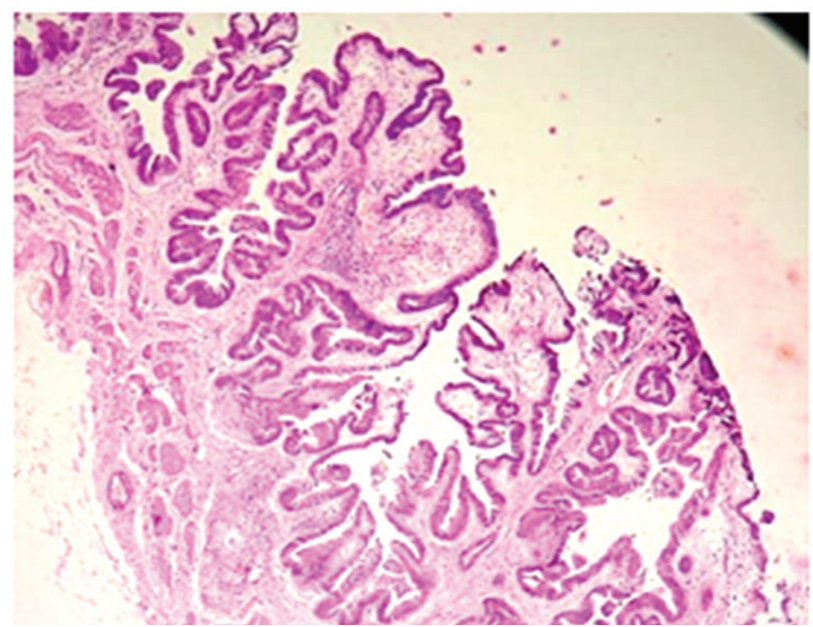

Figure 2. ICPN with low grade dysplasia (Haematoxylin and Eosin $(H$ and $E) \times 40 X)$ 


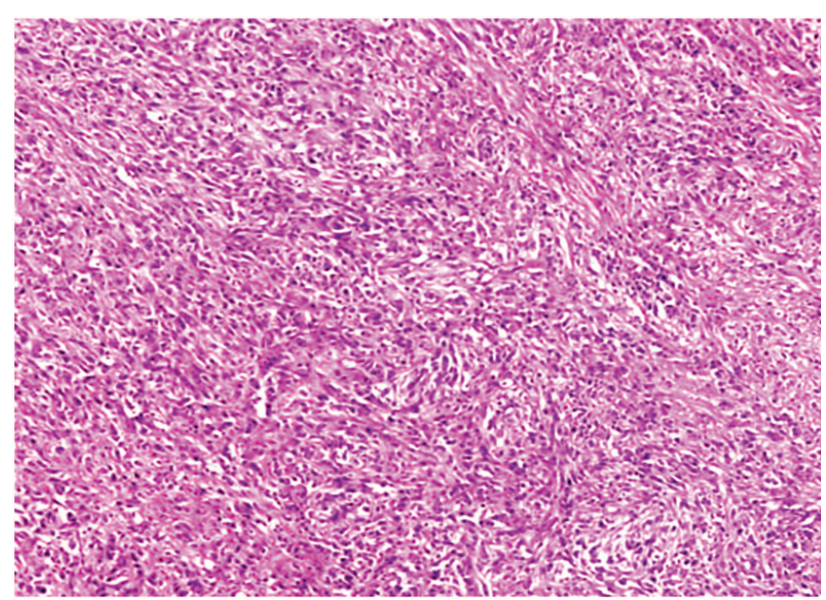

Figure 3. Undifferentiated carcinoma ( $\mathrm{H}$ and $\mathrm{E} \times 40 \mathrm{X})$

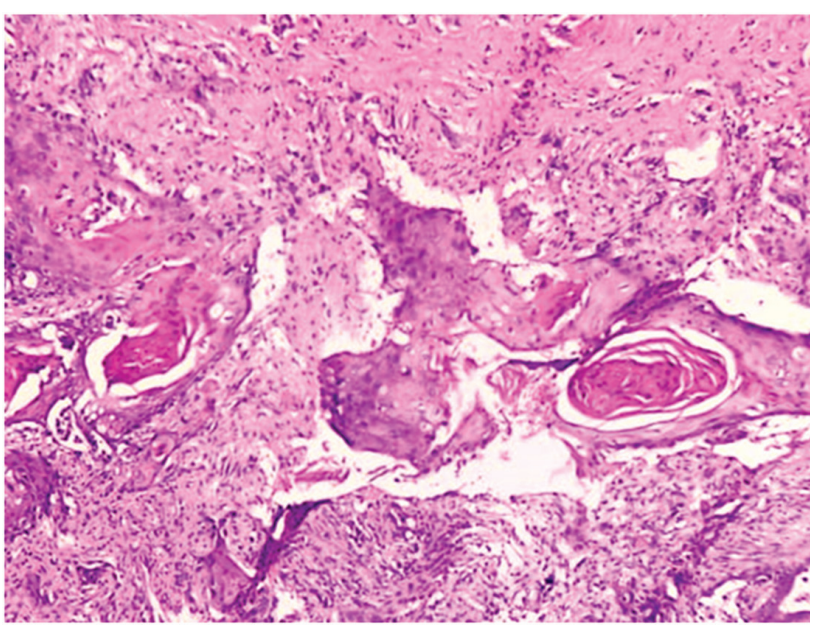

Figure 4. Squamous component in adenosqaumous carcinoma ( $H$ and $E x 40 X)$

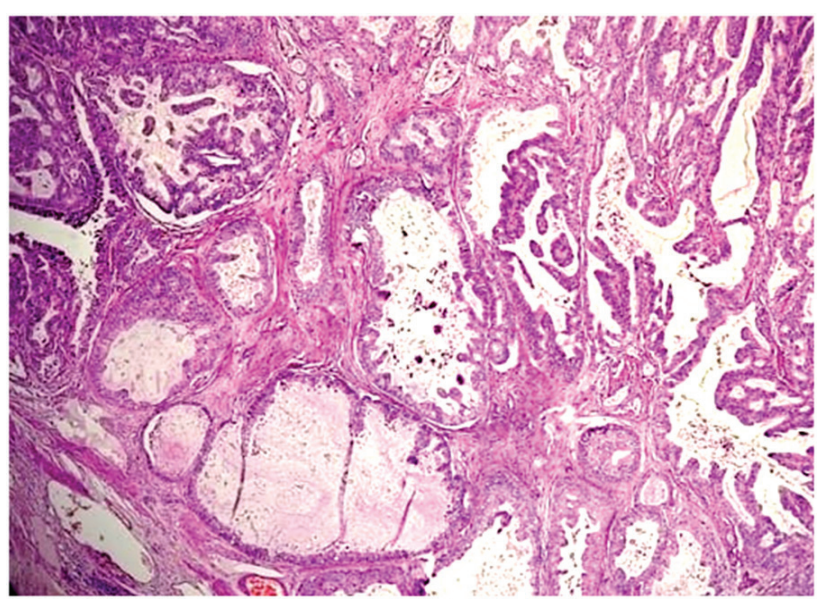

Figure 5. Intestinal type adenocarcinoma ( $\mathrm{H}$ and $\mathrm{E} \times \mathrm{40X}$ )

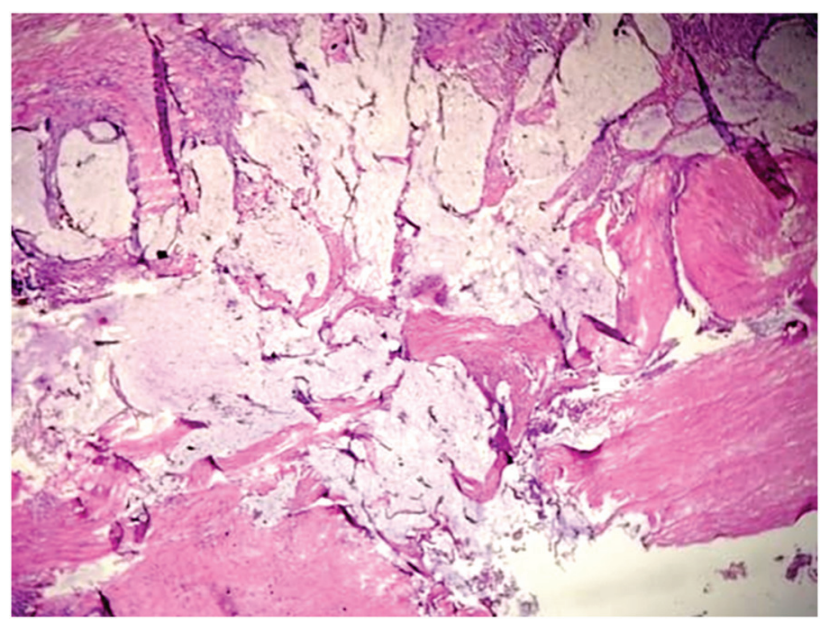

Figure 6. Mucinous adenocarcinoma ( $\mathrm{H}$ and $\mathrm{E} \times 40 \mathrm{X})$

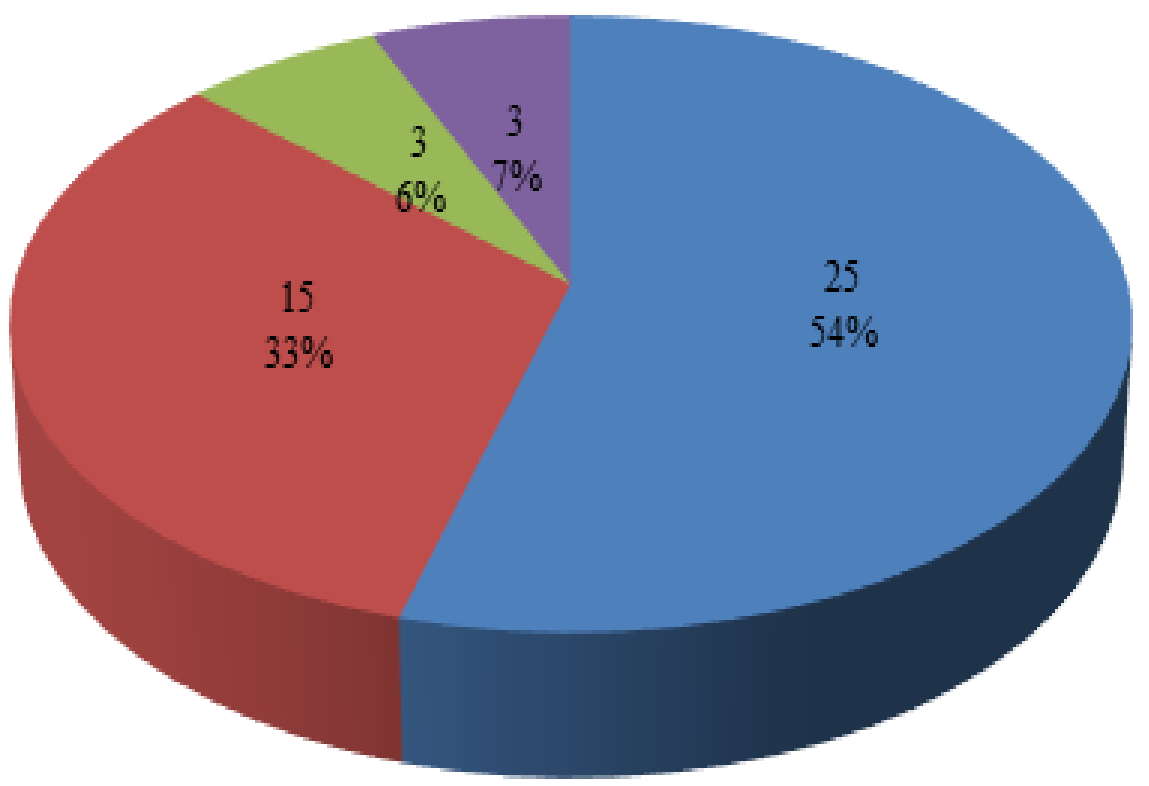

E Fundus

-Body

Neck

Diffuse involving more than one site

Figure 7. Pie chart showing site of lesion in malignant cases $(n=46)$ 
Histological diagnoses of premalignant and malignant conditions are presented in Table 2. BillN cases were $3(5.4 \%)$ cases of high grade dysplasia or biliary intraepithelial neoplasia 3 (Billn-3) and $1(1.8 \%)$ case was low grade dysplasia or biliary intraepithelial neoplasia 1 (Billn-1). All cases of ICPN had low grade dysplasia. All the adenomas were pyloric gland type with $2(3.6 \%)$ having tubular architecture and $1(1.8 \%)$ having
(Figure 7). Grossly, $29(63.0 \%)$ cases were diffusely infiltrating, $13(28.3 \%)$ cases were exophytic growths and $4(8.7 \%)$ cases had papillary growths.

Twenty (43.5\%) cases were moderately differentiated followed by $17(37.0 \%)$ cases which were well differentiated. $15(32.6 \%)$ cases had invaded muscularis propria only followed by $15(32.6 \%)$ cases extending up to serosa (Table 3).

Table 3. Histological differentiation and extent of tumor invasion in malignant cases $(n=46)$

\begin{tabular}{|c|c|c|c|c|c|}
\hline \multirow{2}{*}{ Tumor extension } & \multicolumn{4}{|c|}{ Histological differentiation } & \multirow{2}{*}{ Total } \\
\cline { 2 - 5 } & $\begin{array}{c}\text { Well } \\
\text { differentiated }\end{array}$ & $\begin{array}{c}\text { Moderately } \\
\text { differentiated }\end{array}$ & $\begin{array}{c}\text { Poorly } \\
\text { differentiated }\end{array}$ & Undifferentiated & \\
\hline Muscularispropria & $8(17.4)$ & $5(10.9)$ & $2(4.3)$ & $0(0)$ & $15(32.6)$ \\
\hline Serosa & $6(13.0)$ & $6(13.0)$ & $1(2.2)$ & $2(4.3)$ & $15(32.6)$ \\
\hline Liver & $2(4.3)$ & $7(15.2)$ & $3(6.5)$ & $0(0)$ & $12(26.1)$ \\
\hline CBD & $0(0)$ & $1(2.2)$ & $1(2.2)$ & $0(0)$ & $2(4.3)$ \\
\hline Gut & $1(2.2)$ & $1(2.2)$ & $0(0)$ & $0(0)$ & $2(4.3)$ \\
\hline Total & $17(37.0)$ & $20(43.5)$ & $7(15.2)$ & $2(4.3)$ & $46(100)$ \\
\hline
\end{tabular}

tubulopapillary architecture. Out of 39 (69.6\%) cases of adenocarcinoma, 33 (58.9\%) cases were biliary type, $3(5.4 \%)$ cases were intestinal type (Figure 5), 2 (3.6\%) cases were signet ring type and $1(1.8 \%)$ case was mucinous type (Figure 6)

Out of 46 malignant cases, fundus was the most common site involved in 25 (54.3\%) cases followed by body in 15 (32.6\%) cases
Malignancy was clinically not suspected in 19 $(41.3 \%)$ cases. Missed clinical diagnosis was not associated with gross morphology ( $p>$ 0.05) (Table 4). Out of 19 cases not clinically suspected as malignancy, $10(52.6 \%)$ had extended till muscularispropria, 5 (26.3\%) had extended till serosa and $4(21.1 \%)$ had extended till liver.

Table 4. Comparison of gross morphology with clinical suspicion of malignancy $(n=46)$

\begin{tabular}{|l|c|c|c|}
\hline \multirow{2}{*}{ Gross morphology } & \multicolumn{2}{c|}{ Clinical diagnosis } & \multirow{2}{*}{ Total } \\
\cline { 2 - 4 } & Malignant & Non malignant & $29(63.0)$ \\
\hline Diffusely infiltrating & $15(32.6)$ & $14(30.4)$ & $13(28.3)$ \\
\hline Exophytic & $9(19.6)$ & $4(8.7)$ & $4(8.7)$ \\
\hline Papillary & $3(6.5)$ & $1(2.2)$ & $46(100)$ \\
\hline Total & $27(58.7)$ & $19(41.3)$ & \\
\hline Likelihood ratio $=1.656, \mathrm{p}=0.473$ & & \\
\hline
\end{tabular}




\section{DISCUSSION}

Diseases of the gallbladder are often underappreciated, though it is affected by variety of pathological processes which have specific clinical correlates. Metaplasia from normal columnar absorptive epithelium to mucinous epithelium may occur in few cases which may progress to dysplasia and further invasive carcinoma. Most adenocarcinomas of gallbladder present at late stage and therefore, highly lethal. ${ }^{14}$

In the present study $17.9 \%$ cases were premalignant and rest were malignant. These were $7.1 \%$ cases of dysplasia (BillN), 5.4\% cases of adenoma and $5.4 \%$ cases of ICTPN.In a study conducted by Kocaoz et al, dysplasia and adenomas were seen in $1 \%$ and $0.5 \%$ of total 5026 cholecystectomies respectively. ${ }^{15}$ In gallbladder, dysplasia-carcinoma or metaplasia-dysplasia-carcinoma sequence is considered more important than adenomacarcinoma sequence as evidenced by presence of metaplasia, dysplasia and carcinoma in situ in $66 \%, 81.3 \%$ and $69 \%$ cases of mucosa adjacent to GBC as compared to presence of adenomatous remnants in only $3 \%$ cases adjacent to GBC in a study conducted by Roa et al. ${ }^{8}{ }^{9} \mathrm{ICPN}$ is a relatively new entity first described by Adsay et al in 2012 for grossly visible non invasive epithelial neoplasm arising from mucosa and projecting into lumen measuring $\geq 1 \mathrm{~cm}$ and was recognized by WHO as preinvasive neoplasm under the name of intracholecystic papillary neoplasm. ${ }^{11,12}$ In a study conducted by Hazarika et al, ICPN comprised $23.5 \%$ of all gallbladder neoplasms. ${ }^{10}$ Compared with other organs of the gastrointestinal tract, clinical features, morphology and diagnostic criteria of precursor lesions of gall bladder and biliary tract are less well characterized due to rarity of cancerous lesions and also poor accessibility of this site. ${ }^{16}$

More than $90 \%$ cases of GBC are seen in patients older than 50 years of age with most patients in sixth or seventh decade of life. ${ }^{1,12}$ In a study conducted by Henson et al in 2665 patients with GBC, $63 \%$ of GBC occurred in patients 70 years or older. ${ }^{17}$ In the present study, GBC was most commonly seen in 41 - 50 years age group comprising $30.4 \%$ cases. A study conducted in North America has also observed increasing incidence of obesity related cancers including GBC in younger individuals. ${ }^{18}$ Females were three times more commonly affected than males in present study. In study conducted by Makhdoomi et al, females were twice more commonly affected. ${ }^{19}$ In study done by Henson et alfemale male ratio was 2.7:1. ${ }^{17}$ Literature also suggests that GBC is $2-4$ times more common in females. ${ }^{1,3,12}$ This disparity in gender may be because gall stones and gallbladderinflammation are more common in females which are known risk factors for GBC. ${ }^{20} 60 \%$ cases of GBC occur in fundus, $30 \%$ in body and $10 \%$ in neck. ${ }^{21}$ In the present study also, fundus was the most common site involved in 54\% cases, followed by body in 33\% cases, neck in $6 \%$ cases and $7 \%$ cases were diffuse involving more than one site.

Approximately, $84 \%$ of GBC are adenocarcinomas and $16 \%$ are others like adenosquamous, squamous and other rarer types. ${ }^{22}$ In the present study, $93.5 \%$ of total malignant cases were adenocarcinoma. In study done by Pavani et al, all the malignant cases were adenocarcinoma. ${ }^{23}$ In study done by Makhdoomi et al, $87.5 \%$ cases were adenocarcinoma. ${ }^{19}$ In study done by Henson et al, 94\% cases were adenocarcinoma. ${ }^{17} 84.6 \%$ cases of total 39 cases of adenocarcinoma were biliary type. Well to moderately differentiated adenocarcinomas of biliary type are the most common epithelial neoplasms of gallbladder. ${ }^{12}$ Well differentiated adenocarcinomas were most common (50\%) in study done by Pavani et al. ${ }^{23}$ Whereas, moderately differentiated tumorswere most common in present study comprising $43.5 \%$ cases. In study 
conducted by Henson et al, poorly differentiated tumors were most common (42.4\%) and authors had observed linear association between grade and survival. ${ }^{17} 7.7 \%, 5.1 \%$ and $2.6 \%$ out of total 39 cases of adenocarcinoma were intestinal type, signet ring cell type and mucinous type respectively. All three, intestinal type, signet ring cell type and mucinous type histology are associated with an aggressive clinical course and poor outcome. ${ }^{24-26}$

Intracholecysticpapillaryneoplasm withinvasive carcinoma was seen in $8.7 \%$ of total 46 malignant cases. Previously known by various now not recommended terminologies like intracystic papillary neoplasm with invasive carcinoma and papillary carcinoma in the WHO 2019 edition, it has good prognosis and better prognosis than conventional gallbladder adenocarcinoma. ${ }^{11,}{ }^{12}$, ${ }^{16} 4.3 \%$ cases out of total malignant cases were undifferentiated carcinoma. Undifferentiated carcinoma of gallbladder is a rare malignant neoplasm which shows a significantly larger tumor size and poorer survival than conventional gallbladder adenocarcinoma. ${ }^{27} 1$ $(2.2 \%)$ case was adenosquamous carcinoma. In a study conducted by Roa et al, adenosquamous carcinoma comprised $4.3 \%$ of total 606 GBC and they found a worse prognosis as compared to conventional GBC. ${ }^{28}$

More than $50 \%$ of $\mathrm{GBC}$ is diagnosed in cholecystectomy specimens presumed to have

\section{REFERENCES}

1. Rosai J. Rosai and Ackerman's Surgical Pathology. 10th ed. New delhi: Elsevier; 2011.

2. Young B, Heath JW, editors. Wheater's functional histology. 4th ed. New York: Elsevier Churchill Livingstones; 2000.

3. Crawford JM, Liu C. Liver and Biliary tract. In: Kumar V, Fausto N, Aster JC, Abbas

benign disease. Remaining whichare clinically diagnosed, also present at late stage due to lack of early clinical features. ${ }^{29}$ Out of total malignant cases, $41.3 \%$ cases were clinically not suspected malignant in present study. In studies conducted by Ghimire et al and Poudel et al in Nepal, incidental GBC in routine cholecystectomies was found in $1.28 \%$ and $1.67 \%$ of total cholecystectomies. ${ }^{30,31}$

Grossly, 70\% of GBC may present as diffusely infiltrating growth and $30 \%$ as polypoid mass. When diffuse, distinction from chronic cholecystitis may be difficult. ${ }^{1} 63.0 \%$ of GBC was diffusely infiltrating in present study and $48.3 \%$ of these diffusely infiltrating growths were clinically not suspected to be malignant.However, statistical association between gross morphology and missed clinical diagnosis was not observed. Hence, routine microscopic examination of all cholecystectomy specimens is mandatory. ${ }^{1}$

\section{CONCLUSION}

GBC though rare, often presents late and hence carries a poor prognosis. Routine histopathological analysis of all the cholecystectomy specimens is mandatory in all the centers as malignancy may be clinically missed. There is no significant association between gross morphology of tumor and clinical suspicion in missed clinical diagnoses.

Conflicts of interest: None declared.

AK. Robbibs and Cotran Pathologic basis of disease. 8th ed. Philadelphia: Elsevier; 2010. p.834-90.

4. Rawla P, Sunkara T, Thandra KC, Barsouk A. Epidemiology of gallbladder cancer. Clinical and experimental hepatology. 2019;5(2):93-102. DOI:10.5114/ ceh.2019.85166

5. Kamna Gupta, Amir Faiz, Rajender Kumar 
Thakral, Alok Mohan and Veena K Sharma. The spectrum of histopathological lesions in Gallbladder in cholecystectomy specimens. Int. J. Clin. DiagnPathol. 2019; 2(.1): 146-51. DOI: 10.33545/pathol.2019.v2.i1c.22

6. Gallbladder [Internet]. Globocan 2020: Cancer today; c2020. Global Cancer Obervatory; 2020 [cited 2020 Feb 25]; [about 4 screens]. Available from: https://gco. iarc.fr/today/data/factsheets/cancers/12Gallbladder-fact-sheet.pdf

7. Sasatomi E, Tokunaga O, Miyazaki K. Precancerous conditions of gallbladder carcinoma: overview of histopathologic characteristics and molecular genetic findings. J Hepatobiliary Pancreat Surg. 2000;7(6):556-67. DOI: 10.1007/s005340070004

8. Roa I, de Aretxabala X, Araya JC, Roa J. Preneoplastic lesions in gallbladder cancer. J Surg Oncol. 2006;93(8):615-23. DOI: $10.1002 /$ jso.20527

9. Kai K. Organ-specific concept and controversy for premalignant lesions and carcinogenesis of gallbladder cancer. HepatobiliarySurgNutr. 2016;5(1):85-7. DOI: 10.3978/j.issn.2304-3881.2016.01.03

10. Hazarika P, Sharma MK. Intracholecystic papillary-tubular neoplasm of gallbladder: A 5-year retrospective pathological study. Indian J Pathol Microbiol. 2018;61(4):516-9. DOI: 10.4103/IJPM.IJPM_489_17

11. Askan G, Basturk O. Intracholecystic papillary neoplasm [Internet]. [Place unknown]: Pathology Outlines. com; 2003[updated 2021 Jan 14; cited 2020 Mar 25] Available from: https:// www.pathologyoutlines.com/topic/ gallbladderipn.html

12. Bosman FT, Carneiro F, Hruban RH, Theise
ND. WHO Classification of Tumors of the Digestive System. 5th ed. Lyon: IARC; 2019.

13. Siddiqui FG, Memon AA, Abro AH, Sasoli NA, Ahmad L. Routine histopathology of gallbladder after elective cholecystectomy for gallstones: waste of resources or a justified act? BMC Surg. 2013;13:26. DOI: 10.1186/1471-2482-13-26

14. Hansel DE, Maitra A, Argani P. Pathology of the gallbladder: a concise review. Current Diagnostic Pathology. 2004; 10(4):304-17. https://doi.org/10.1016/j. cdip.2004.03.006

15. Kocaoz S, Turan G. Preneoplastic and neoplastic gallbladder lesions detected after cholecystectomy. PrzGastroenterol. 2019;14(3):193-7.DOI: 10.5114/pg.2019.82675

16. Adsay VN. Neopalstic Precursors of the Gallbladder and Extrahepatic Biliary System. GastroenterolClin N Am. 2007;36(4):889-900. https://doi. org/10.1016/j.gtc.2007.08.011

17. Henson DE, Albores-Saavedra J, Code D. Carcinoma of the gallbladder. Histologic types, stage of disease, grade, and survival rates. Cancer. 1992;70(6):1493-7. doi:10.1002/1097 0142 (19920915) $70: 6<1493$ : : a i d cncr2820700608>3.0.co;2-u

18. Sung H, Siegel RL, Rosenberg PS, Jemal A. Emerging cancer trends among young adults in the USA: analysis of a populationbased cancer registry. Lancet Public Health. 2019;4(3):e137-47. doi: 10.1016/ S2468-2667(18)30267-6. Epub 2019 Feb 4.

19. Makhdoomi R, Bashir $\mathrm{N}$, Bhat $\mathrm{N}$, Bashir S, Mustafa F, Aiman A, et al. Clinicopathological Spectrum Of Gallbladder Cancer In Kashmir - An 
Institutional Study. The Gulf J Oncolog. 2016;1(20):79-85. https://pubmed.ncbi.nlm. nih.gov/27050183/

20. Gallbladder Cancer Causes, Risk Factors, and Prevention [Internet]. American Cancer Society; [cited 2020 Mar 15]; [about 13 screens]. Available from: https://www. cancer.org/cancer/gallbladder-cancer/ causes-risks-prevention.html.

21. Akki AS. Gallbladder carcinoma [Internet]. [Place unknown]: Pathology Outlines. com; 2003[updated 2020 April 21; cited 2020 Mar 31] Available from: https:// www.pathologyoutlines.com/topic/ gallbladdercarcinoma.html

22. Dowling GP, Kelly JK. The histogenesis of adenocarcinoma of the gallbladder. Cancer. 1986;58(8):17028.doi:10.1002/10970142(19861015) 58:8<1702::aidcncr2820580821>3.0.co;2-z.

23. Pavani M, Anunayi J, Vivekanand N, Deshpande AK.Histomorphological spectrum of Gallbladder lesions, relation to p53 expression. Indian Journal of Pathology and Oncology. 2020;7(2):235-42. https://doi.org/10.18231/j.ijpo.2020.045

24. Albores-Saavedra J, Cruz-Ortiz H, Alcantara-Vazques A, Henson DE. Unusual types of gallbladder carcinoma. A report of 16 cases. Arch Pathol Lab Med. 1981;105(6):287-93. https://pubmed.ncbi. nlm.nih.gov/6263212/

25. Pudasainin S, Subedi N, Prasad KB, Rauniyar SK, Bhattacharya SK, Koirala $\mathrm{R}$, et al. Signet ring cell carcinoma of the gallbladder: a case report. Nepal Med Coll J. 2011;13(4):308-10. https://pubmed.ncbi. nlm.nih.gov/23016488/

26. Dursun N, Escalona OT, Roa JC, Basturk O, Bagci P, Cakir A, et al. Mucinous carcinomas of the gallbladder: clinicopathologic analysis of 15 cases identified in 606 carcinomas. Arch Pathol Lab Med. 2012;136(11):1347-58.doi: 10.5858/arpa.2011-0447-OA.

27. Park HJ, Jang KT, Choi DW, Heo JS, Choi SH. Clinicopathologic analysis of undifferentiated carcinoma of the gallbladder. J HepatobiliaryPancreat Sci. 2014;21(1):58-63.doi: 10.1002/jhbp.3.

28. Roa JC, Tapia O, Cakir A, Basturk O, Dursun N, Akdemir D, et al. Squamous cell and adenosquamous carcinomas of the gallbladder: clinicopathological analysis of 34 cases identified in 606 carcinomas. Mod Pathol. 2011;24(8):1069-78.DOI:10.1038/ modpathol.2011.68

29. Keilson JM, Maithel SK. The Undertreatment of Gallbladder Cancer: Gaps in Seeking, Reaching, and Receiving Care. Ann Surg Oncol. 2021. https://doi. org/10.1245/s10434-021-09761-x

30. GhimireP, YogiN, Shrestha BB. Incidence of incidental carcinoma Gallbladder in cases of routine cholecystectomy. Kathmandu Univ Med J (KUMJ). 2011;9(34):3-6. DOI: 10.3126/kumj.v9i2.6278

31. Poudel R, Shah A. Incidence of Incidental Gallbladder Cancer and Role of Routine Histopathological Examination in Cholecystectomies Specimens for Benign Disease. J Nepal Health Res Counc. 2020;18(3):547-50.DOI: $\quad$ 10.33314/jnhrc. v18i3.1974

Citation: Goyal B, Sedhain M, Subedi P, Rai S. Histopathologic Profile of Premalignant and Malignant Lesions of Gallbladder. JCMS Nepal. 2021; 17(4); 322-30. 